\title{
Data report: Pleistocene paleomagnetic and rock magnetic records from IODP Site U1312 on the southern flank of the King's Trough'
}

\author{
Toshiya Kanamatsu, ${ }^{2}$ Gary Acton, ${ }^{3}$ Helen Evans, ${ }^{4}$ Yohan Guyodo, ${ }^{5}$ and Masao Ohno ${ }^{6}$
}

\section{Chapter contents}

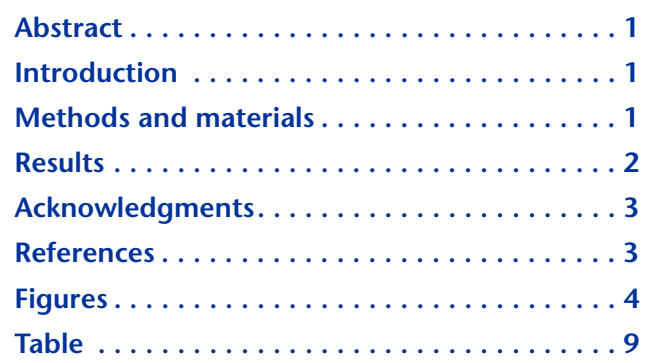

'Kanamatsu, T., Acton, G., Evans, H., Guyodo, Y., and Ohno, M., 2010. Data report: Pleistocene paleomagnetic and rock magnetic records from IODP Site U1312 on the southern flank of the King's Trough. In Channell, J.E.T., Kanamatsu, T., Sato, T., Stein, R., Alvarez Zarikian, C.A., Malone, M.J., and the Expedition 303/306 Scientists, Proc. IODP, 303/306: College Station, TX (Integrated Ocean Drilling Program Management International, Inc.).

doi:10.2204/iodp.proc.303306.208.2010

${ }^{2}$ Institute for Research on Earth Evolution, Japan Agency for Marine-Earth Science and Technology, 2-15 Natsushima-cho, Yokosuka, Kanagawa 2370061, Japan. toshiyak@jamstec.go.jp ${ }^{3}$ Department of Geology, University of California, Davis, One Shields Avenue, Davis CA 95616, USA. ${ }^{4}$ Department of Geological Sciences, University of Florida, 241 Williamson Hall, PO Box 112120, Gainesville FL 32611-2120, USA.

Present address: Marine Geology and Geophysics, Lamont-Doherty Earth Observatory, Columbia University, PO Box 1000, 61 Route 9W, Palisades NY 10964, USA.

${ }^{5}$ Laboratoire des Sciences du Climat et de I'Environnement, Campus du CNRS, 12 Ave de la Terrasse, 91198 Gif-sur-Yvette Cedex, France. Present address: Institut de Mineralogie et de Physique des Milieux Condensés, 140 rue de Lourmel, 75015, France.

${ }^{6}$ Department of Environmental Changes, Faculty of Social and Cultural Studies, Kyushu University, 744 Motooka, Nishi-ku, Fukuoka 819-0395, Japan. Present address: Department of Environmental Changes, Faculty of Social and Cultural Studies, Kyushu University, 744 Motooka, Nishi-ku, Fukuoka 819-0395, Japan.

\section{Abstract}

Paleomagnetic and rock magnetic studies were conducted on sediment obtained from Integrated Ocean Drilling Program Site U1312 in order to construct an age model for understanding spatial and temporal changes in North Atlantic paleoceanography. Paleomagnetic directions suggest that the sedimentary sequence from 0 to $59.6 \mathrm{~m}$ composite depth (mcd) covers geomagnetic polarities from 0 to $3.6 \mathrm{Ma}$. Although high fluctuations of magnetic mineral concentrations in most studied intervals are inadequate for a relative paleomagnetic intensity (RPI) study, proxies of RPI in the interval $16.9-46 \mathrm{mcd}$, which is relatively constant in magnetic mineral concentrations, represent an RPI pattern similar to previous North Atlantic data. This similarity suggests good potential for further age control using RPI on sediments from Site U1312.

\section{Introduction}

Holes U1312A $\left(42^{\circ} 50.2040^{\prime} \mathrm{N}, 2^{\circ} 5.2506^{\prime} \mathrm{W}\right.$; water depth $\left.=3522 \mathrm{~m}\right)$ and U1312B $\left(42^{\circ} 50.2150^{\prime} \mathrm{N}, 23^{\circ} 5.2652^{\prime} \mathrm{W}\right.$; water depth $\left.=3523 \mathrm{~m}\right)$ were cored to reoccupy Deep Sea Drilling Project Hole 608 during Integrated Ocean Drilling Program Expedition 306 on the southern King's Trough, which is located northeast of the Azores Islands (Fig. F1). A continuous paleoceanographic record at this site is fundamental to understanding Quaternary-Miocene sea-surface temperature (SST) temporal variations, which are needed to achieve the expedition objectives. Site U1312 occupies the key geographical position in this theme because the region between $40^{\circ}$ and $50^{\circ} \mathrm{N}$ is considered to have been sensitive to SST changes in the North Atlantic through geologic time. One of the most important issues to be established in this project is construction of a detailed age model at a sub-Milankovitch scale. $\delta^{18} \mathrm{O}$ and relative paleomagnetic intensity (RPI) studies were assigned as stratigraphic templates for this purpose. We measured and analyzed the magnetization of sediments from Site U1312 to acquire paleomagnetic data and assess whether the quality of magnetic data is suitable for RPI study.

\section{Methods and materials}

Sediment was cored using the advanced piston coring system of the R/V JOIDES Resolution. The lithology at Site U1312 is composed of varying mixtures of biogenic and detrital components. 
Carbonate content of the sediment seems to be controlled by glacial and interglacial cycles. For example, the lightness record $\left(\mathrm{L}^{*}\right)$ of sediment color from 0 to 40 meters below seafloor (mbsf) in Hole U1312B generally can be correlated to the global benthic $\delta^{18} \mathrm{O}$ stack (see the "Site U1312" chapter). A total of 105 U-channel subsamples $(2 \mathrm{~cm} \times 2 \mathrm{~cm} \times 150 \mathrm{~cm})$ were collected from splice sections from Holes U1312A and U1312B. The composite depth scale (mcd) was adopted as the depth scale of the spliced samples (see the "Site U1312" chapter). Splicing of the sections at Site U1312 was incomplete because of severe coring disturbances, especially in the interval between 65.24 and 74.5 mcd (Sections 306-U1312A$7 \mathrm{H}-5$ through $8 \mathrm{H}-8$ ). Because this situation prevented continuous interpretation of magnetic data downhole, magnetic measurements were made only in the interval between 0 and 65.24 mcd.

Natural remanent magnetization (NRM) of U-channel samples was measured using a $2 \mathrm{G}$ Enterprises horizontal cryogenic magnetometer at $1 \mathrm{~cm}$ intervals. Alternating-field (AF) demagnetization was carried out at 20, 25, 30, 35, 40, 45, 50, 60, 70, and 80 mT (Fig. F2). Subsequently, anhysteretic remanent magnetization (ARM) with a $100 \mu \mathrm{T}$ biasing field and an AF demagnetization field of $80 \mathrm{mT}$ was applied and then demagnetized at the same levels of NRM. Magnetic susceptibility $(k)$ was measured at $1 \mathrm{~cm}$ intervals using a Bartington Instruments MS2 susceptibility meter with a $4 \mathrm{~cm}$ diameter loop sensor. Directions of NRM characteristic remanent magnetizations were calculated by principal component analysis (PCA) (Kirschvink, 1980). Data are available in NRM_PCA in "Supplementary material."

\section{Results}

\section{Magnetic concentration}

Susceptibility $(k)$ and ARM represent concentrations of magnetic minerals in a sample. Wide variations in the $k$ and ARM profiles are observed in the upper sedimentary interval (0-15 mcd) with larger amplitudes and longer periods of fluctuation; smaller amplitudes and shorter periods show less fluctuation in the lower interval (15-65 mcd) (Fig. F3). The interval between 15 and 47 mcd shows gradual decreases in the concentrations of magnetic minerals. Fairly low and unclear cycle patterns of $k$ and ARM are observed in sections below 29 mcd.

The fluctuating pattern of magnetic concentration possibly reflects carbonate content, which might be correlated to the $\delta^{18} \mathrm{O}$ pattern as $\mathrm{L}^{*}$ (see the "Site U1312" chapter). The fluctuating pattern between 0 and $10 \mathrm{mcd}$ might correlate to the benthic $\delta^{18} \mathrm{O}$ pat- tern (Lisiecki and Raymo, 2005), but the pattern of the interval between 10 and 15 mcd is not clear. The interval from 15 to 29 mcd can be correlated to the $\delta^{18} \mathrm{O}$ pattern again according to onboard correlation (see the "Site U1312" chapter) and the paleomagnetic data below. Fairly low and indistinct patterns in magnetic concentrations below 29 mcd differ from $\delta^{18} \mathrm{O}$ patterns. Most portions of cores are not ideal for RPI study because of the highly fluctuating magnetic mineral contents. One proposed criteria for RPI study is that the maximum concentration must be no more than $10 \times$ the minimum concentration (e.g., Tauxe, 1993).

\section{Paleomagnetic direction}

Because each U-channel sample was measured separately, data from both ends of the U-channel (top and bottom $10 \mathrm{~cm}$ ) were eliminated from analysis in order to avoid the edge effect of superconducting quantum interference device (SQUID) sensors. Maximum angular deviation (MAD) values calculated by PCA are usually $<4^{\circ}$, but intervals at polarity boundaries are larger, as high as $45.6^{\circ}$ (Fig. F4). The inclination profile obtained after PCA indicates normal and reversed polarity intervals (Fig. F4). Inclinations above 37 mcd are clearly biased to the normal or reversed sides, but below this horizon the inclination pattern is unclear. Particularly the interval between 37 and 50 mcd involves prominent short intervals of positive inclination in the dominantly reversed interval. Because the inclination pattern in the interval between 55 and 59.5 mcd presumably correlates to Chron C2An (Gauss) according to the onboard biostratigraphy results (see the "Site U1312" chapter); the spiky normal intervals from 46.13 to $46.86 \mathrm{mcd}$ could correspond to Chron C2n (Olduvai). The identified chrons and subchrons are given in Table T1.

\section{Paleointensity proxy}

Relative paleointensity proxies are calculated only in the interval between 16.91 and 46.13 mcd (from the Brunhes/Matuyama chron boundary to the possible top of the Olduvai Chron), which shows relatively smaller variations in magnetic mineral concentrations. NRM intensity at $20 \mathrm{mT}$ demagnetization is normalized by ARM intensity at $20 \mathrm{mT}$ and $k$ (NRM20mT/ARM20mT and NRM20mT/k) (Fig. F5), and both are compared with the paleointensity data at Ocean Drilling Program Site 984 in the North Atlantic (Channell et al., 2002). The decrease in the proxies just below the bottom of the Jaramillo event (23 mcd) in the data produced from Site U1312 is distinctly different from Site 984 data. Although the cause of this decrease is unclear so far, the inclina- 
tion profile reveals two short zones of normal polarity between 23 and 25 mcd (Fig. F4). Thus, it is supposed that the low is related to a short subchron such as the Cobb Mountain event. The paleointensity proxy patterns in the interval between 25 and 36 mcd are similar to the interval from $~ 1200$ to 1470 $\mathrm{ka}$ at Site 984 . The proxy values at Site U1312 below 36 mcd drastically decrease, but the pattern seems to correlate to the profile of Site 984.

\section{Acknowledgments}

We would like to thank IODP Expedition 303/306 colleagues for encouraging discussion and useful suggestions on this work. I thank my colleagues at the Japan Agency for Marine-Earth Science and Technology (JAMSTEC) for support during the cruise and postcruise research. This research used samples and data provided by Integrated Ocean Drilling Program (IODP). Funding for this postcruise research was provided by JAMSTEC.

\section{References}

Channell, J.E.T., Mazaud, A., Sullivan, P., Turner, S., and Raymo, M.E., 2002. Geomagnetic excursions and paleointensities in the Matuyama Chron at Ocean Drilling Program Sites 983 and 984 (Iceland Basin). J. Geophys. Res., [Solid Earth], 107(B6):2114. doi:10.1029/ 2001JB000491

Kirschvink, J.L., 1980. The least-squares line and plane and the analysis of palaeomagnetic data. Geophys. J. R. Astron. Soc., 62(3):699-718.

Lisiecki, L.E., and Raymo, M.E., 2005. A Pliocene-Pleistocene stack of 57 globally distributed benthic $\delta^{18} \mathrm{O}$ records. Paleoceanography, 20(1):PA1003. doi:10.1029/ 2004PA001071

Tauxe, L., 1993. Sedimentary records of relative paleointensity of the geomagnetic field: theory and practice. Rev. Geophys., 31(3):319-354. doi:10.1029/93RG01771

Initial receipt: 9 May 2008

Acceptance: 7 January 2010

Publication: 16 April 2010

MS 303306-208 
Figure F1. Location of IODP Site U1312 on the southern King's Trough, North Atlantic.

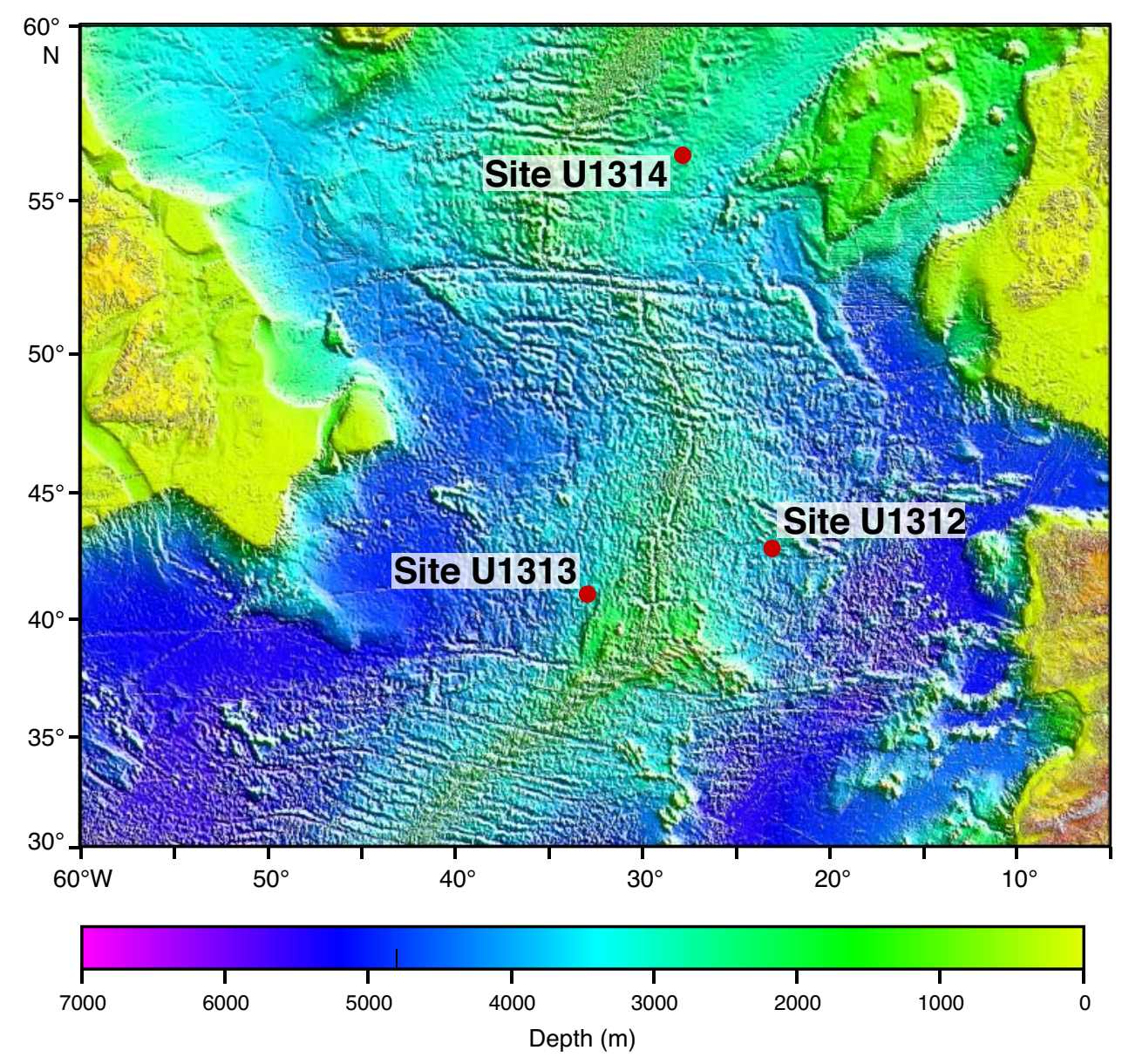


Figure F2. Representative orthogonal projections of AF demagnetization experiments. Solid circles $=$ vertical plane, open squares = horizontal plane. A. Sample 303-U1312B-2H-4, 26 cm. B. Sample 303-U1312A-4H-4, 22 cm. C. Sample 303-U1312B-4H-1, 69 cm. D. Sample 303-U1312B-6H-4, $97 \mathrm{~cm}$.

A

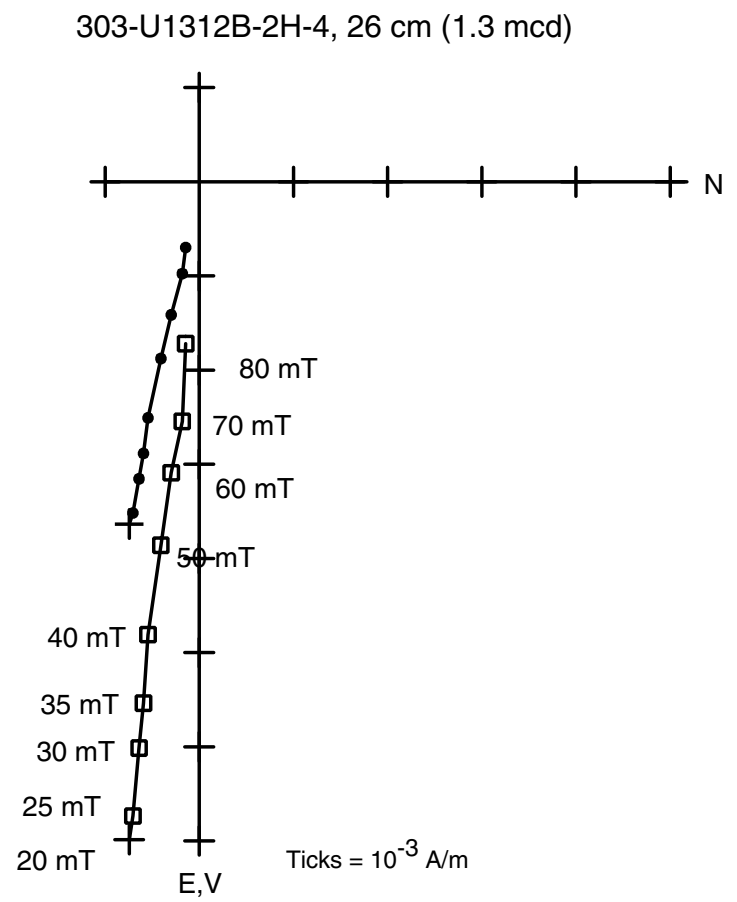

C

303 U1312B-4H-1, $69 \mathrm{~cm}(23.59 \mathrm{mcd})$

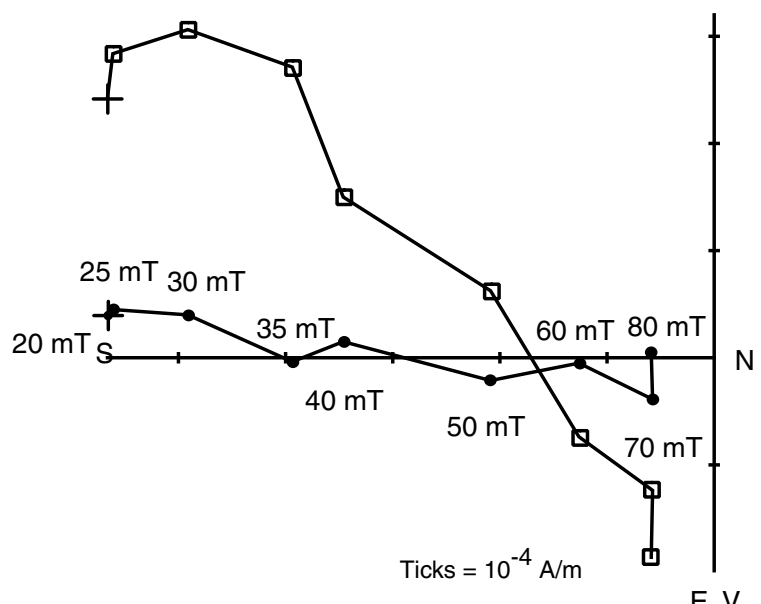

B 303-U1312A-4H-4, $22 \mathrm{~cm}(27.62 \mathrm{mcd})$

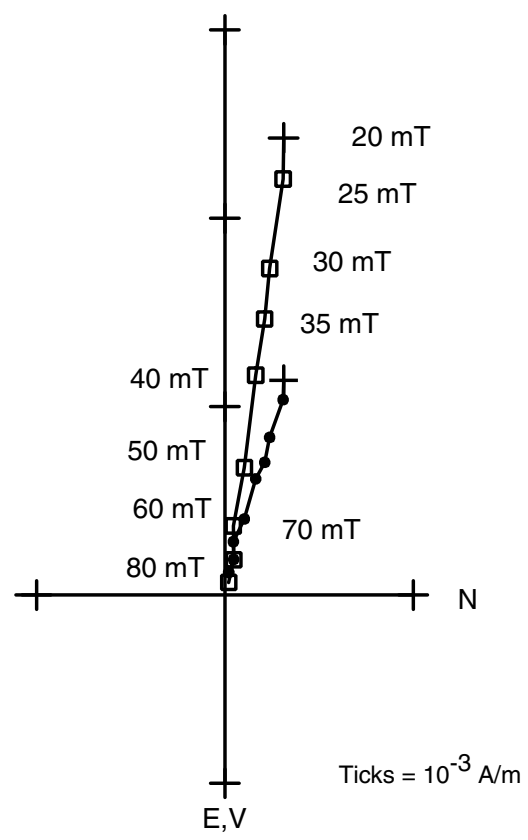

D 303-U1312B-6H-4, $97 \mathrm{~cm}(47.37 \mathrm{mcd})$

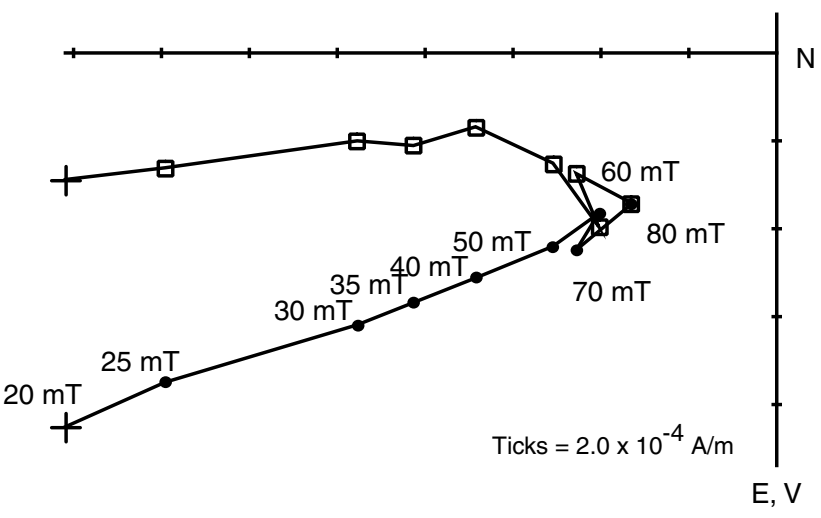


Figure F3. Correlation between (A) magnetic concentration, $(\mathbf{B})$ lightness $\left(\mathrm{L}^{*}\right)$, and $(\mathbf{C})$ global benthic oxygen isotope stack (Lisiecki and Raymo, 2005). ARM = anhysteretic remanent magnetization.
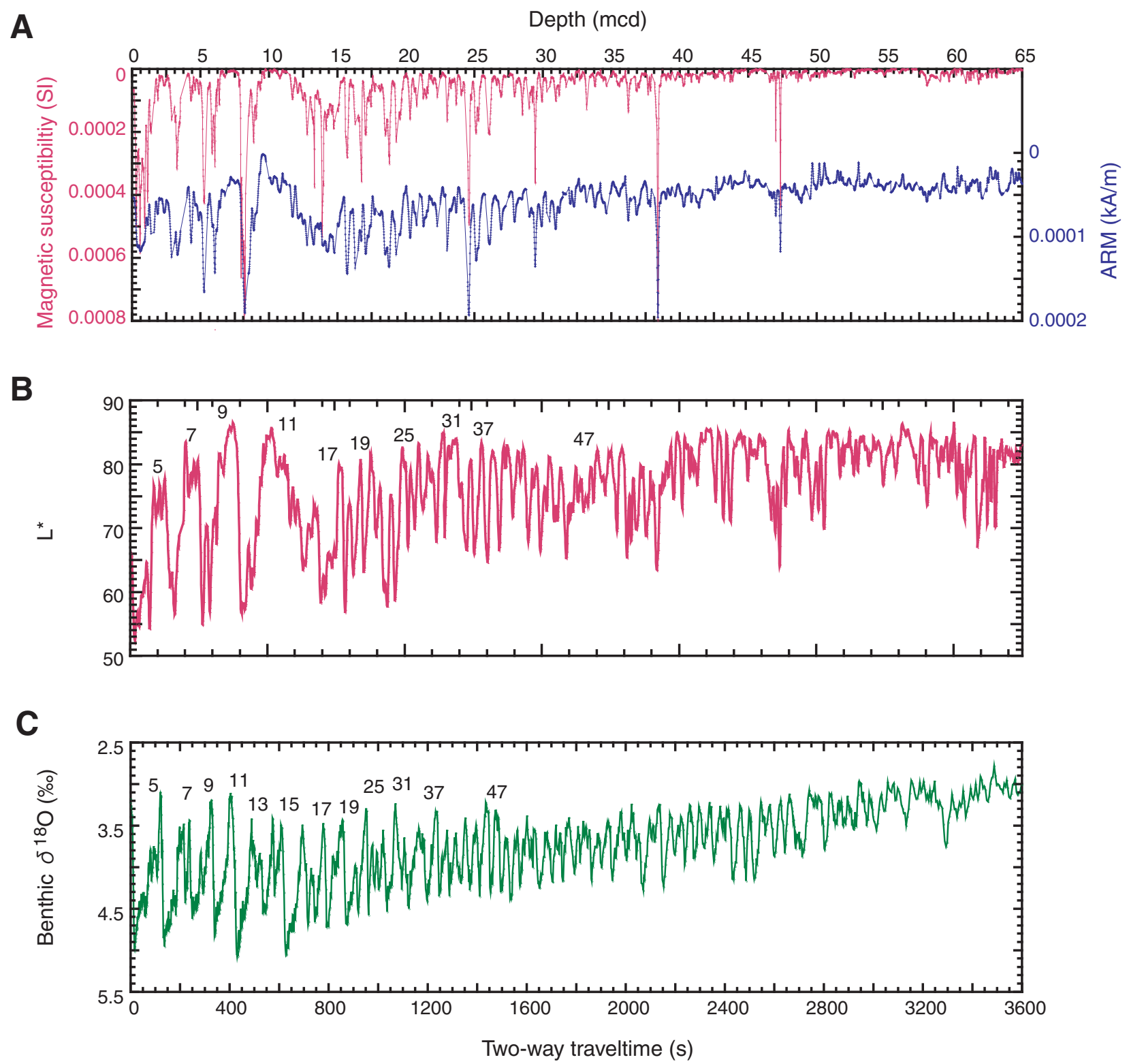
Figure F4. Inclination values plotted against depth, Site U1312. Data obtained after principal component analysis (Kirschvink, 1980) and maximum angular deviation (MAD) values.
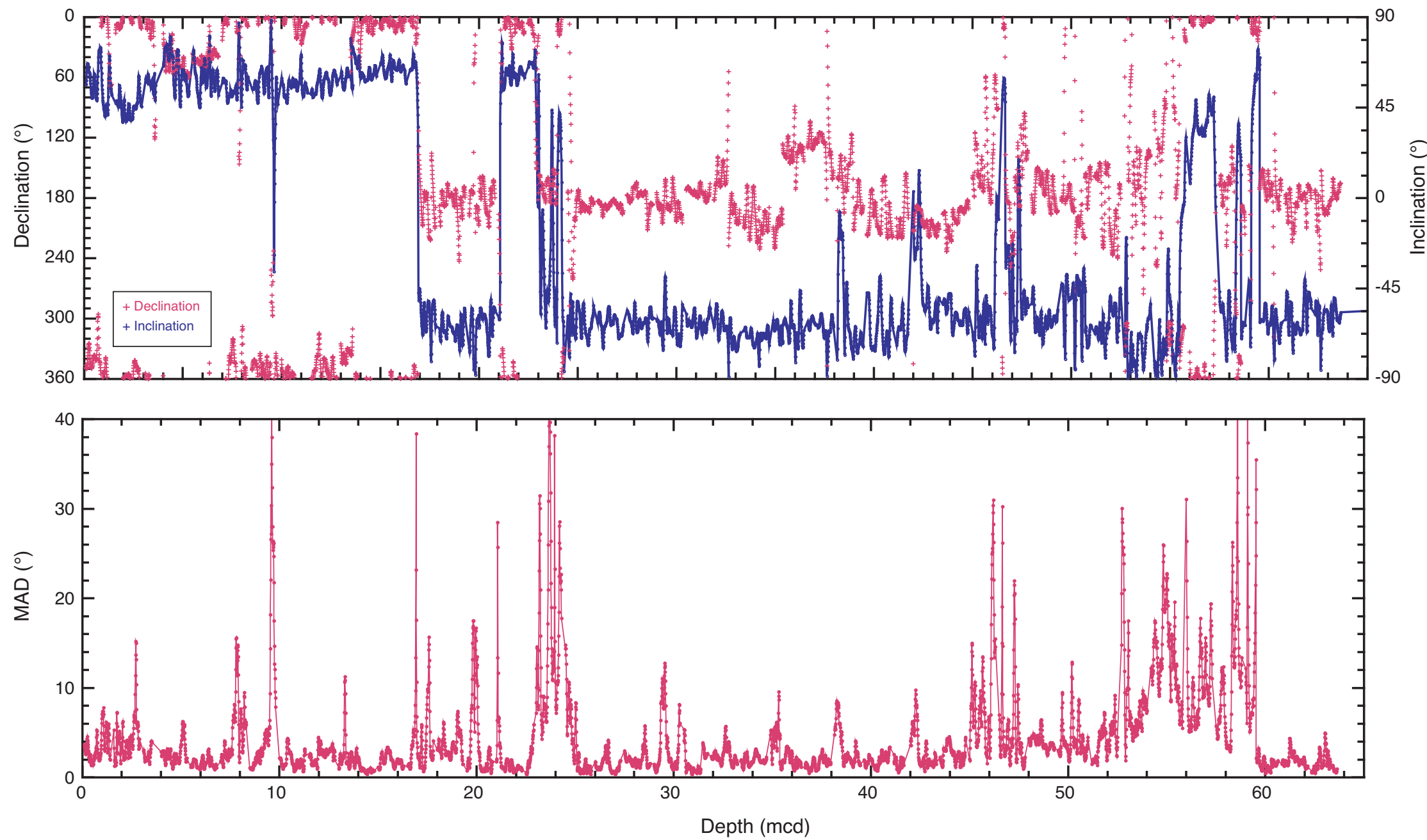
Figure F5. Paleointensity proxies of NRM20mT/ARM20mT and NRM20mT/k.

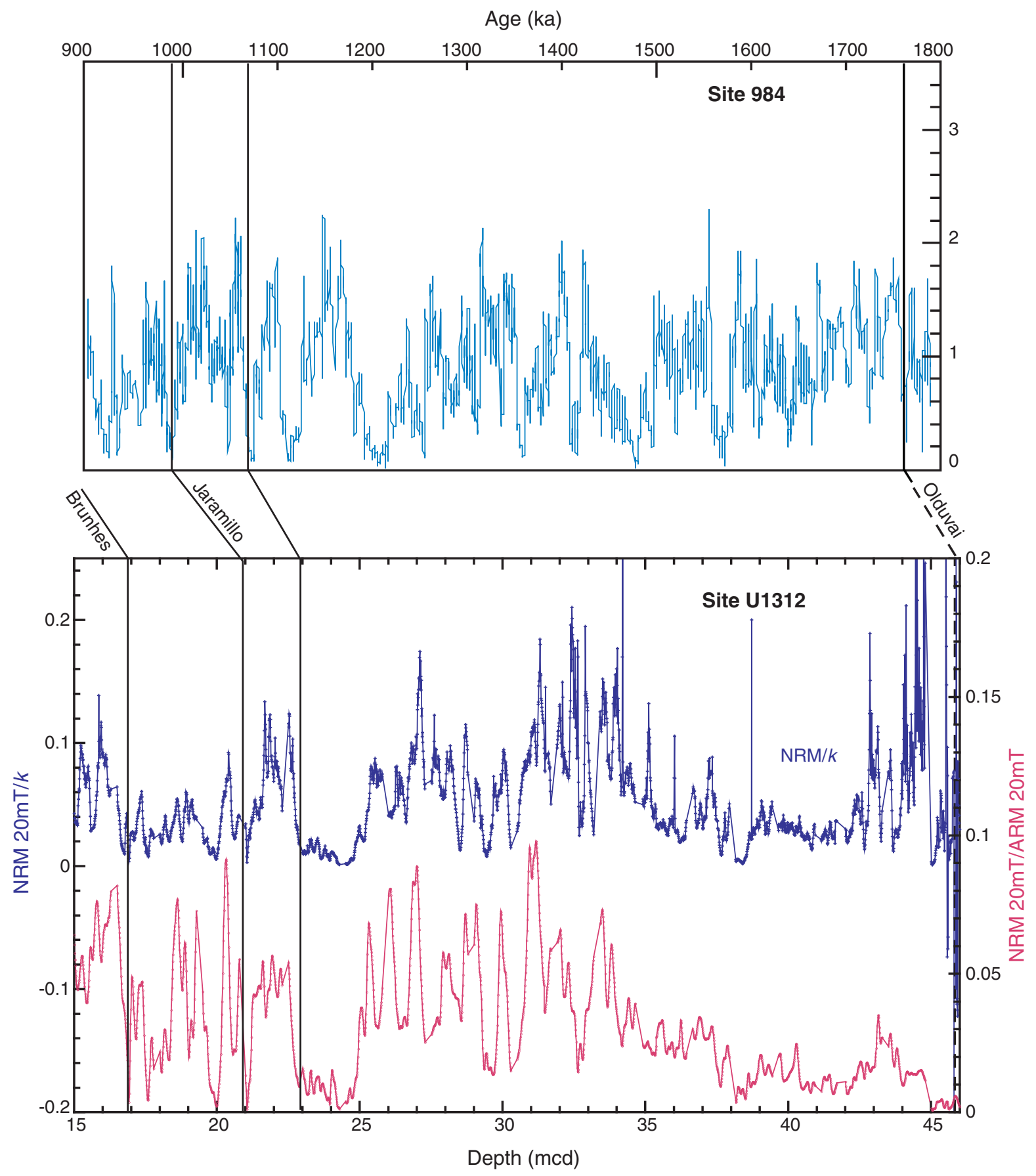


Table T1. Geomagnetic polarity boundaries. (See table note.)

\begin{tabular}{lll}
\hline \multicolumn{1}{c}{ Polarity chron boundary } & $\begin{array}{c}\text { Age } \\
(\mathrm{Ma})\end{array}$ & $\begin{array}{c}\text { Depth } \\
(\mathrm{mcd})\end{array}$ \\
\hline C1n bottom: Brunhes/Matuyama & 0.78 & 16.91 \\
C1r.1n top: Jaramillo top & 0.99 & 21.06 \\
C1r.1n bottom: Jaramillo bottom & 1.07 & 23.06 \\
C2n top: Olduvai top & 1.77 & $46.13(?)$ \\
C2n bottom: Olduvai bottom & 1.95 & $46.86(?)$ \\
\hline
\end{tabular}

Note: ? = uncertainty. 